\title{
Numerical investigation of the location of maximum erosive wear damage in elbow: Effect of slurry velocity, bend orientation and angle of elbow
}

\author{
Hao Zhang a,b, Yuanqiang Tan ${ }^{\text {a,* }}$, Dongmin Yang ${ }^{\text {a,c }}$, Francesc Xavier Trias ${ }^{\text {b }}$, Shengqiang Jiang ${ }^{a}$, \\ Yong Sheng ${ }^{c}$, Assensi Oliva ${ }^{b}$ \\ a School of Mechanical Engineering, Xiangtan University, Hunan 411105, China \\ ${ }^{\mathrm{b}}$ Heat and Mass Transfer Technological Center, Technical University of Catalonia, Terrassa, 08222, Spain \\ c School of Civil Engineering, University of Leeds, Leeds LS2 9JT, UK
}

\section{A R T I C L E I N F O}

\section{Article history:}

Received 9 August 2011

Accepted 3 November 2011

Available online 10 November 2011

\section{Keywords:}

DEM

Puncture point location

Slurry velocity

Bend orientation

\begin{abstract}
A B S T R A C T
A numerical simulation of fluid transportation process was carried out focused on the investigation into predicting the location of the puncture point location in elbow. The kinematics and trajectory of the discrete particles as well as the particle-particle interaction were described by discrete element method (DEM) while the hydrodynamic model of the fluid phase was based on the volume-averaged Navier-Stokes equations, and a fluid density-based buoyancy model was adopted to calculate the solid-fluid interaction force. In this paper, the spatial distribution of particle-wall interaction force was calculated and corresponded to the wear pattern in the elbow, the puncture point locations have been observed. In particular, the influences of slurry velocity, bend orientation and angle of elbow on the puncture point location were discussed.
\end{abstract}

(c) 2011 Elsevier B.V. All rights reserved.

\section{Introduction}

Damage of fluid handling equipment due to erosive wear can cause significant operation and reliability problems in oil and gas, coal, slurry, aerospace, pneumatic conveying, bulk material handling and other industries [1]. Severe erosion takes place on the pipe due to the impact of solid particles on the pipe wall, particularly at its elbow (as shown in Fig. 1). The erosion phenomenon is highly complicated due to a number of parameters affecting the erosion severity, such as production flow rate, entrained solid rate in production fluid, fluid properties, flow regime, solid particle properties, particle geometry, wall material of equipment, and geometry of the equipment as stated by Chen et al. [2]. Solid particle velocity which affected by fluid velocity and fluid property has been recognized as the most significant factor for erosion by some investigators and several models were proposed based on that for single-phase liquid or gas flow contained solid particles $[3,4]$. To prevent process equipment failure and downtime, it's necessary to identify the puncture point location. Experimental investigations were carried out by Mazumder [1,5] and SelmerOlsen [6] to characterize the location and magnitude of erosion in elbow specimens. Selmer-Olsen's experiments were conducted in gas-liquid (mixture) multiphase vertical annular flow with quartz particles, and during Mazumder's investigation, experiments were

\footnotetext{
* Corresponding author.

E-mail address: tanyq@xtu.edu.cn (Y. Tan).
}

conducted in both single and multiphase flows in elbows to identify the location of maximum erosion. A mechanistic model for multiphase flow was proposed in [5]. In our previous work [7], the concrete pumping process was modeled with the location of maximum erosive wear damage in elbow predicted. The simulation results showed that the wear pattern in an elbow depended on the magnitude of the interaction forces and the frequency of interactions between particles and wall. Research into the bend failure on a pneumatic conveyor undertaken by Burnett [8] mentioned that the puncture locations of the bends might vary with different bend geometry. However, the effect of variations in bend orientation was not included in his study. Deng [9] conducted experiments with four bend orientations to investigate the effect of bend orientation on puncture point location, finding that the puncture point location is indeed significantly influenced by the bend orientations.

In this study, we used a fluid-solid multi-phase flow model to investigate the erosion in the elbow during transportation, where the continuum modeling proposed by Anderson and Jackson [10] was employed to evaluate the flow field of the slurry. A fluid density-based buoyancy model (FDB) [11] was adopted to approach the interaction force between slurry fluid and the solid particles, while a so-called discrete element method (DEM) [12] was used to describe the trajectory of particles and interactions between the particles or between particles and wall. As pointed out by $\mathrm{Yu}$ and $\mathrm{Xu}$ [13], the current CFD-DEM coupling scheme is attractive because of its superior computational convenience as compared to Direct Numerical Simulation- $[14,15]$ or Lattice Boltzmann-DEM [16] and capability to capture the particle physics as compared to Two Flow Model [17]. The focus of this study 


$\begin{array}{ll}\text { Nomenclature } \\ a & \text { acceleration of the particle, } \mathrm{m} / \mathrm{s}^{2} \\ C_{D} & \text { the fluid drag coefficient } \\ d_{p i} & \text { diameter of particle } i, \mathrm{~m} \\ f_{d i} & \text { drag force on a single particle, } \mathrm{N} \\ f_{f p i} & \text { interaction force between fluid and a single particle, } \mathrm{N} \\ F_{c} & \text { normal contact force between the elements, } \mathrm{N} \\ \Delta F_{s} & \text { tangential force between the elements (ball or wall), } \mathrm{N} \\ g & \text { acceleration of gravity, } \mathrm{m} / \mathrm{s}^{2} \\ I & \text { moment of inertia, } \mathrm{kg} \cdot \mathrm{m}^{2} \\ k_{n} & \text { normal stiffness, } \mathrm{N} / \mathrm{m} \\ k_{s} & \text { tangential stiffness, } \mathrm{N} / \mathrm{m} \\ m & \text { mass of the particle, } \mathrm{kg} \\ n_{e} & \text { number of particles in one fluid element } \\ p & \text { fluid pressure, Pa } \\ \partial t & \text { time step, } \mathrm{s} \\ \mathrm{Re}_{p i} & \text { particle Reynolds number } \\ \Delta S & \text { the shear component of the contact displacement in- } \\ T & \text { crement, } \mathrm{m} \\ T & \text { total number of the simulation timesteps } \\ u & \text { fluid velocity, } \mathrm{m} / \mathrm{s} \\ u_{j} & \text { fluid velocity at the position where the particle is, } \mathrm{m} / \mathrm{s} \\ v_{i} & \text { velocity of particle } i, \mathrm{~m} / \mathrm{s} \\ v_{p i} & \text { volume of particle } i, \mathrm{~m}{ }^{3}\end{array}$

\section{Greek letters}

$\delta \quad$ overlap between the elements

$\varepsilon \quad$ porosity

$\theta \quad$ angular position, rad

$\mu \quad$ fluid viscosity, $\mathrm{kg} /(\mathrm{m} \cdot \mathrm{s})$

$\rho_{f} \quad$ density of fluid, $\mathrm{kg} / \mathrm{m}^{3}$

$\tau \quad$ the torque, $\mathrm{N} \cdot \mathrm{m}$

$\tau_{f} \quad$ the viscous stress the effect of slurry velocity, bend orientation and angle of elbow on the puncture point location were investigated. Numerical results at different slurry velocities are compared with the experimental results in [1] and [6], while numerical results with different bend orientations are compared with the experimental results in [9]. Note that particlewall interaction force was adopted to stand for the erosion severity in this study while the experimental investigations were primarily focused on the determination of mass loss or thickness loss on the wall, so the validation of numerical modeling against experimental data is qualitative.

The rest of the paper is organized as follows. We summarized the fluid phase of slurry flow model and the FDB model in the next section. A brief description of the DEM theory is given in Section 3 where more detailed formulations are referred to PFC3D CCFD Add-on User manual $[18,19]$. PFC3D CCFD Add-on is a popular commercial code of fluid-solid two-phase flow and is used as the simulation platform of [7] and this research; finally, in Section 4, the simulations of fluid transportation at different flow conditions are performed with results discussed.

\section{Equations of slurry motion}

The continuity and momentum equations in the fluid are based on local mean variables as derived by Anderson and Jackson [10].

$\frac{\partial\left(\varepsilon \rho_{f}\right)}{\partial t}+\nabla \cdot\left(\varepsilon \rho_{f} u\right)=0$

$\frac{\partial\left(\varepsilon \rho_{f} u\right)}{\partial t}+\nabla \cdot\left(\varepsilon \rho_{f} u \otimes u\right)=-\nabla p+\nabla \cdot \varepsilon \tau_{f}+(1-\varepsilon) \nabla p-n_{e} \varepsilon f_{d i}+\varepsilon \rho_{f} g$

where $u$ and $\rho_{f}$ are the fluid velocity and density, respectively. $\varepsilon$ is the porosity. $p$ is the fluid pressure, $\tau_{f}$ is the viscous stress. $g$ is the gravitational acceleration. $n_{e}$ is the number of particles in one fluid cell. $f_{d i}$ is the drag force which is given by [11]:

$f_{d i}=\frac{1}{2} C_{D} \rho_{f} \frac{\pi d_{p i}^{2}}{4} \varepsilon_{j}^{2}\left|u_{j}-v_{i}\right|\left(u_{j}-v_{i}\right) \varepsilon_{j}^{-(\chi+1)}$ to investigate the wear process of the pipe and eventually to predict the location of maximum erosive wear damage in the elbow. In particular,

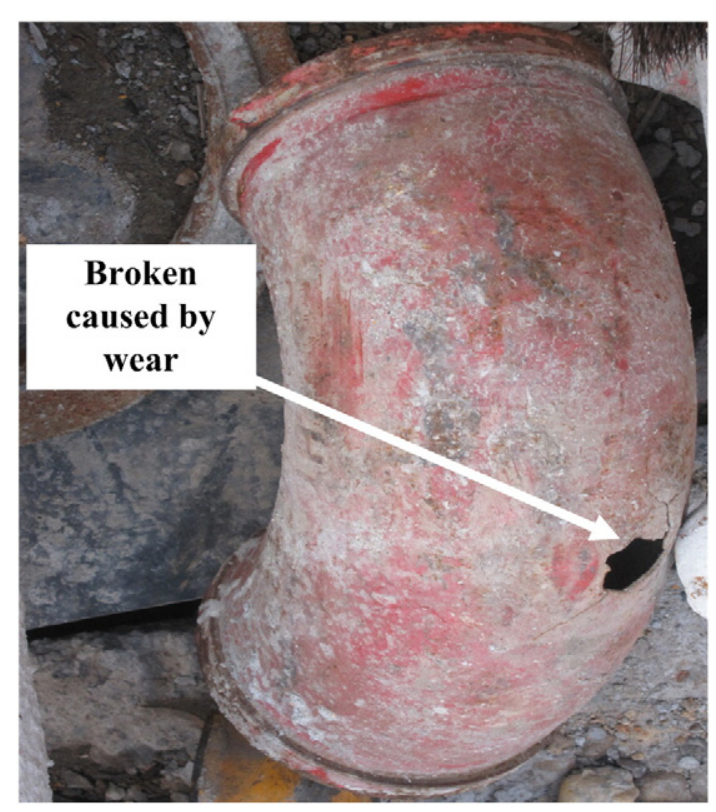

Fig. 1. The destroyed pipe in concrete pumping process. where the subscript $j$ denotes the fluid computational cell in which particle $i$ resides, and the $\varepsilon_{j}^{-(\chi+1)}$ term is an empirical factor to account for the local porosity. The empirical coefficient $\chi$ is defined as:

$\chi=3.7-0.65 \exp \left[-\frac{\left(1.5-\log _{10} \mathrm{Re}_{p i}\right)^{2}}{2}\right]$

$C_{D}$ is the fluid drag coefficient for a single unhindered particle

$C_{D}=\left[0.63+\frac{4.8}{\operatorname{Re}_{p i}^{0.5}}\right]^{2}$

where the particle Reynolds number $\mathrm{Re}_{p i}$ is based on the superficial slip velocity between particle and fluid

$\operatorname{Re}_{p i}=\frac{\rho_{f} d_{p i} \varepsilon_{j}|u-v|}{\mu}$

where $\mu$ is the dynamic viscosity of the fluid. Note that $(1-\varepsilon) \nabla p-$ $n \varepsilon f_{d i}+\varepsilon \rho_{f} g$ in Eq. (2) will be regarded as a source term when solving the fluid equations. The way we used to calculate the interaction force is called the fluid density-based buoyancy model (FDB) [11]. 


\section{DEM modeling of the interaction between moving particles}

The discrete element method (proposed by Cundall [12]) was used to account for the interactions between particles and the walls. When taking into account all the forces acting on each particle, the dynamic equations of the discrete element can be symbolically expressed as:

$\left\{\begin{array}{l}m a=F_{c}+f_{f p i}+m g \\ I \frac{\partial^{2} \theta}{\partial t^{2}}=\tau\end{array}\right.$

where $m$ and $I$ are respectively the mass and the moment of inertia of a particle; $\theta$ is the angular position; $g$ is the gravitational acceleration; $\tau$ is torque. $f_{f p i}$ is the fluid-solid interaction force which defined as:

$f_{f p i}=-v_{p i} \nabla p+v_{p i} \nabla \cdot \tau_{f}+\varepsilon f_{d i}$

where $v_{p i}$ is volume of particle $i$.

A linear spring model is used to present the contact between elements as follow:

$\left\{F_{c}=k_{n} \delta\right.$

$\left\{F_{s}=-k_{s} \Delta S\right.$

where $k_{n}$ and $k_{\mathrm{s}}$ are the normal and tangential stiffness, respectively. $\delta$ is the overlap of the elements. $\Delta S$ is the shear component of the contact displacement increment. The shear contact force is computed in an incremental fashion. When the contact is formed, the total shear contact force is initialized to zero. Each subsequent relative sheardisplacement increment results in an increment of elastic shear force that is added to the current value.

\section{Numerical illustration}

\subsection{Simulation condition}

It was confirmed in [7] that the current solid-fluid combining approach provided a promising solution strategy for investigation of the wear process of the pipeline. As an expanded research, in this study we adopt the same simulation parameters from [7] as a standard case (as shown in Fig. 2). To study the effect of slurry velocity, bend orientation and angle of bend, other results will be compared with those obtained from the standard case. In the standard case, the length of the horizontal pipe is $1.6 \mathrm{~m}$, the length of the vertical pipe is $0.6 \mathrm{~m}$, the elbow section consists a $90^{\circ}$ circular bend with an outer radius of $0.4 \mathrm{~m}$ and an inner radius of $0.3 \mathrm{~m}$. The length of the elbow is about
$0.628 \mathrm{~m}$, the diameter of the pipe is $0.1 \mathrm{~m}$. The position of particles at the inlet was generated in such a way that in the inlet of the horizontal pipe, initial velocity of the particles is $6 \mathrm{~ms}$, and the velocity at the inlet is set $6 \mathrm{~m} / \mathrm{s}$ keeping constant, while the pressure at the outlet is 0 .

Parameters of material content are shown in Table 1 employed from [20]. Collocated grid was used to arrange fluid variables in center of a fluid computational cell, and the whole computational domain was divided by 2000 CFD cells. Patankar's SIMPLE algorithm [21] was adopted to compensate the pressure and velocity to satisfy the conservation law of mass.

Noted that to determine appropriate value of $k_{n}$ and $k_{s}$ in Eq. (9), a trial and error approach was employed. In this study, $k_{n}=1 \times 10^{7} \mathrm{~N} /$ $\mathrm{m}$ and $k_{s}=1 \times 10^{7} \mathrm{~N} / \mathrm{m}$.

\subsection{Results and discussion}

\subsubsection{The standard case}

The hydraulic pressure and velocity magnitude distribution in standard case were obtained and discussed in [7] as well as the particle concentration. It was indicated in [7] that the particle motion was influenced by fluid property and the maximum impact force on the wall played an important role in the wear process. In the present paper, the maximum impact force distribution was adopted to represent the wear pattern on the elbow. The wear processes in different flow conditions were investigated by changing the slurry velocities, bend orientation and angle of bend.

Fig. 3(a) and (b) shows the instantaneous spatial distribution of the porosity and fluid-particle interaction force at $0.2 \mathrm{~s}$. As shown in Fig. 3(a), a rope is formed in the elbow and the particle segregation is very obvious. The fluid-particle interaction force (shown in Fig. 3 (b)) reaches its maximum in the region of highest particle concentration. This can be explained as follows according to Eq. (3): (i) The porosity is small in this region where the particles concentrated, the drag force on a particle is large when the porosity is low, the relationship between porosity and drag force has been summarized by Kafui et al. in [22]. (ii) The relative velocity between the two phases is large in this region, the drag force on a particle is large when the relative velocity between the phases is large. The large relative velocity is due to two aspects. On one hand, the friction between the particles and wall decelerates the velocity of the particles; on the other hand, collisions take place most frequently in this region, particles may stay or even bounced back caused by the collisions between particles.

\subsubsection{Effect of the slurry velocity on the puncture point location}

In this section, to study the effect of the slurry velocities on the puncture point location, simulations were conducted by changing the

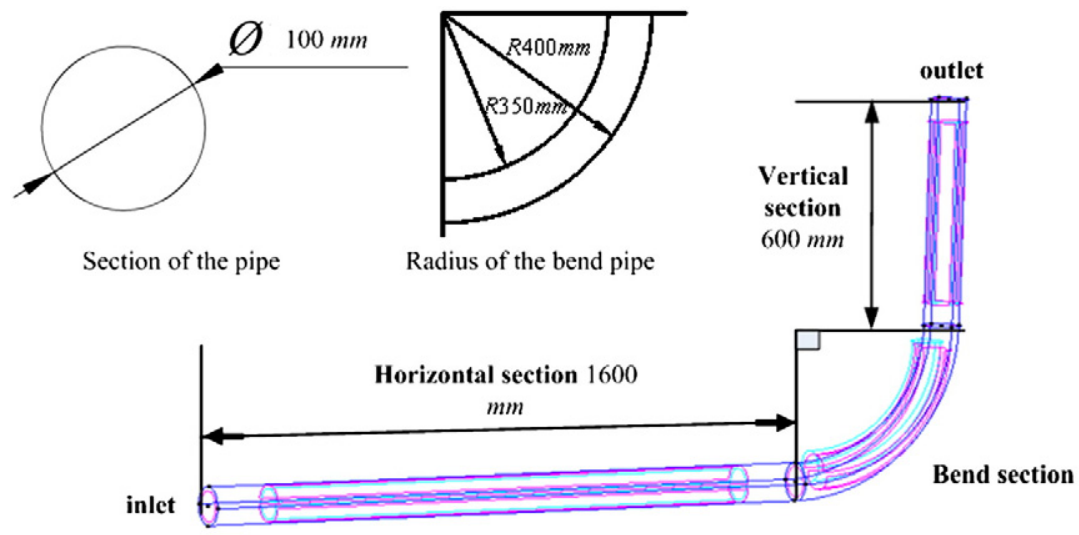

Fig. 2. Diagram of the computational domain. 
Table 1

Parameters of material content.

\begin{tabular}{llll}
\hline Phase & Density $/\left(\mathrm{kg} / \mathrm{m}^{3}\right)$ & Diameter of particle $/ \mathrm{m}$ & Volume fraction \\
\hline Fluid & 3100 & $\mathrm{X}$ & $25 \%$ \\
Solid (small) & 2960 & 0.002 & $49 \%$ \\
Solid (large) & 2960 & 0.015 & $26 \%$ \\
\hline
\end{tabular}

slurry velocities while leaving other parameters same as those in the standard case. Fig. 4 illustrates the maximum impact force distribution on the elbow at different slurry velocities when the gravity action is ignored. Fig. 4(a) shows the maximum impact force distribution when the slurry velocity is $6 \mathrm{~m} / \mathrm{s}$, it can be seen that the maximum erosive location is observed at approximately $42^{\circ}$ of the outer wall (degrees are defined in Fig. 7(a)). Due to the maximum flow velocity is at the centerline of the pipe, the corresponding impact velocity at the centerline of the pipe is also maximum. This causes the maximum erosion near the intersection of the inlet flow centerline and the surface of the outer radius of the elbow. In this study, the centerline of inlet flow intersects the outer wall of the elbow at approximately $25^{\circ}$. When the slurry velocity increases from $6 \mathrm{~m} / \mathrm{s}$ to $9 \mathrm{~m} / \mathrm{s}, 18 \mathrm{~m} / \mathrm{s}$ and $36 \mathrm{~m} / \mathrm{s}$, it is found in Fig. 4(b), (c) and (d) that the maximum erosive location does not change very much. For example, Fig. 4(d) shows the maximum erosion at approximately $47^{\circ}$ which is $5^{\circ}$ downstream from the puncture point of the standard case as shown in Fig. 4(a). But when the slurry velocity is higher, the particle-wall interaction force is higher as shown in the legends.

Fig. 5 shows the peak magnitude of the maximum impact force at different slurry velocities. The peak magnitude of the maximum interaction force at slurry velocity $36 \mathrm{~m} / \mathrm{s}$ is approximately 7.2 times higher than that in standard case, while the velocity is 6 times higher than the velocity in standard case $(6 \mathrm{~m} / \mathrm{s})$. It can be seen from Fig. 5 that when the slurry velocity increases from $6 \mathrm{~m} / \mathrm{s}$ to $9 \mathrm{~m} / \mathrm{s}$, the peak magnitude of the maximum impact force increases following a linear way; whereas the peak magnitude of the maximum impact force increases faster than the linear case when the slurry velocity increases from $9 \mathrm{~m} / \mathrm{s}$ to $18 \mathrm{~m} / \mathrm{s}$ and $36 \mathrm{~m} / \mathrm{s}$.

Fig. 6 illustrates the max impact force distribution at different slurry velocities versus the location in elbow. It can be seen from Fig. 6 that the interaction force is generally higher when the slurry velocity is higher, and 3 peaks were observed at approximately 15,40 and $89^{\circ}$ according to the trend of the lines. The first two peaks are due to the direct strike of particles from the horizontal pipe, and the fluid-solid drag force in
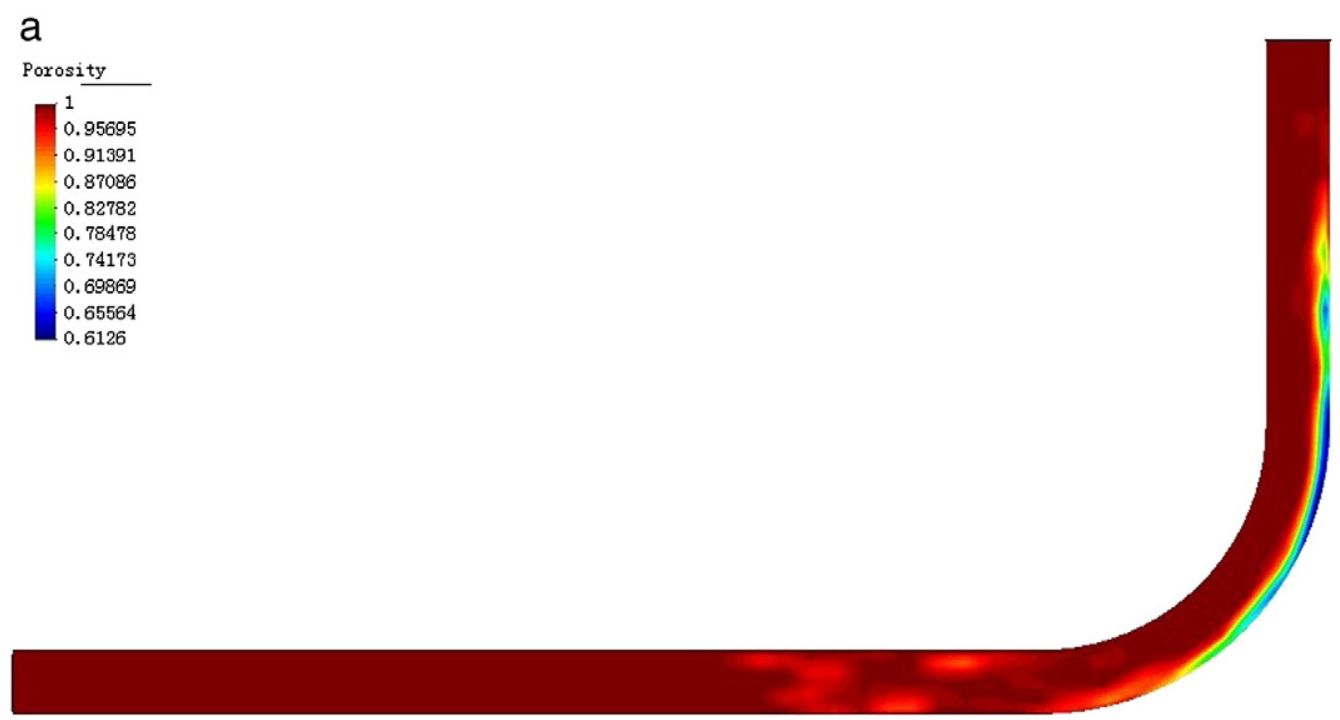

b

Mag

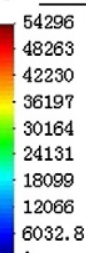

Fig. 3. Spatial distribution of (a) porosity and (b) fluid-particle interaction force $\left(\mathrm{N} / \mathrm{m}^{3}\right)$ at $0.2 \mathrm{~s}$. 
a

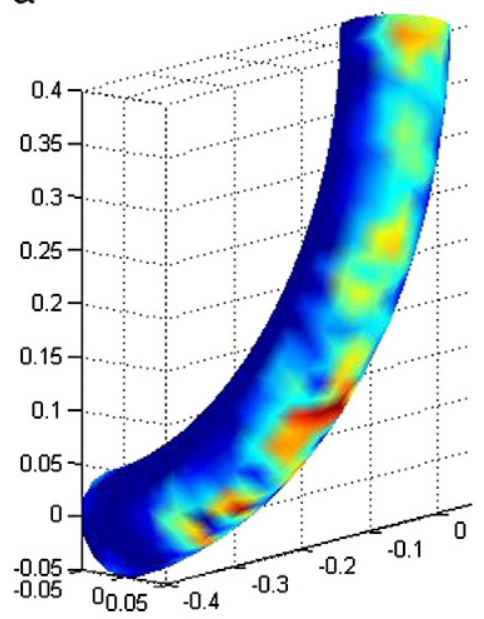

C

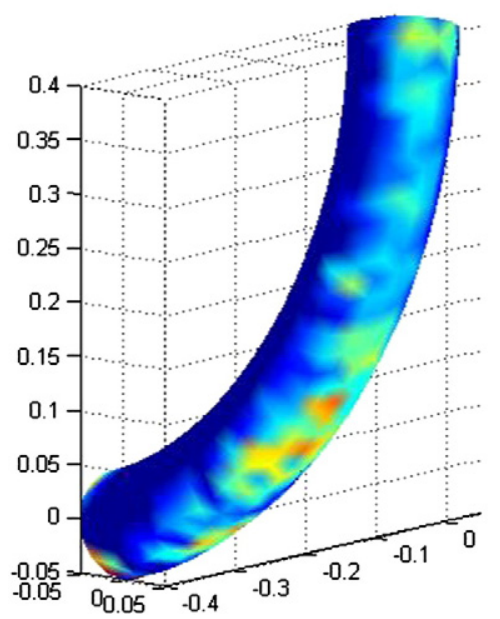

b
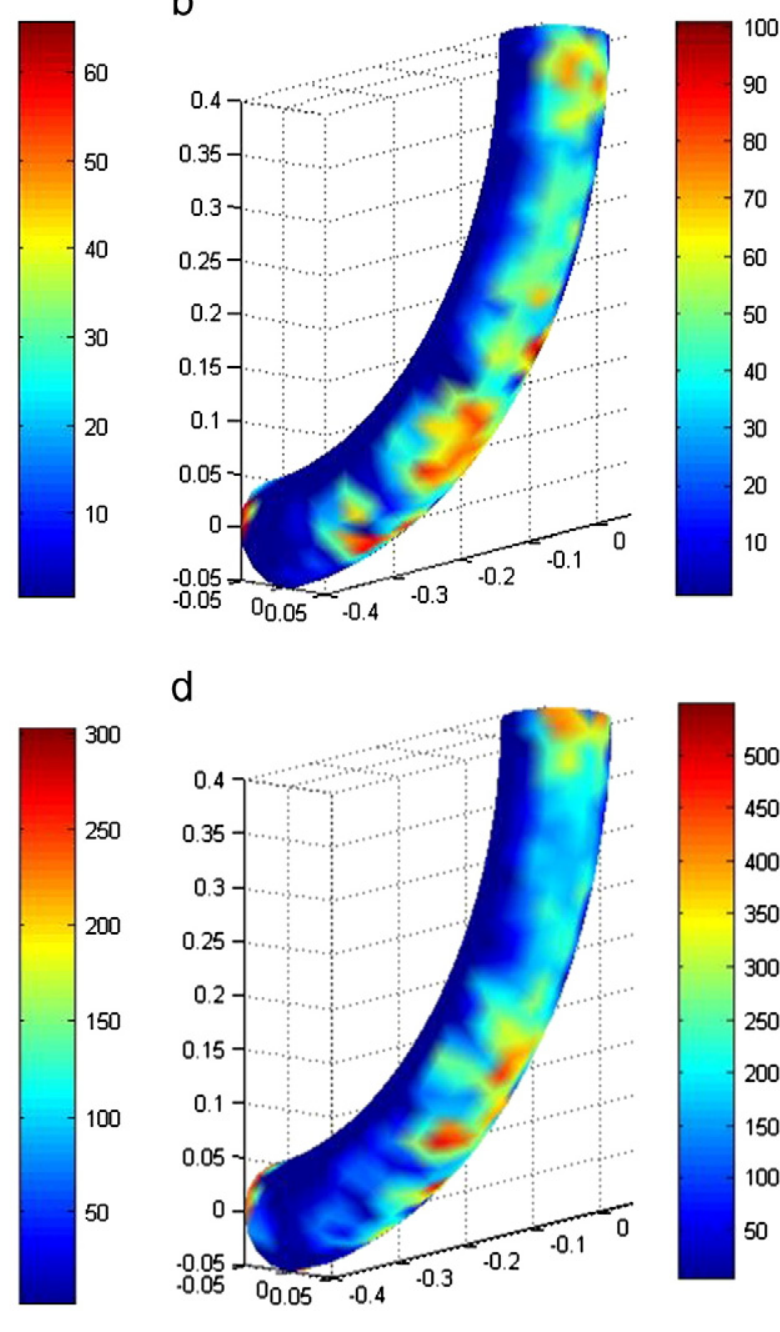

d

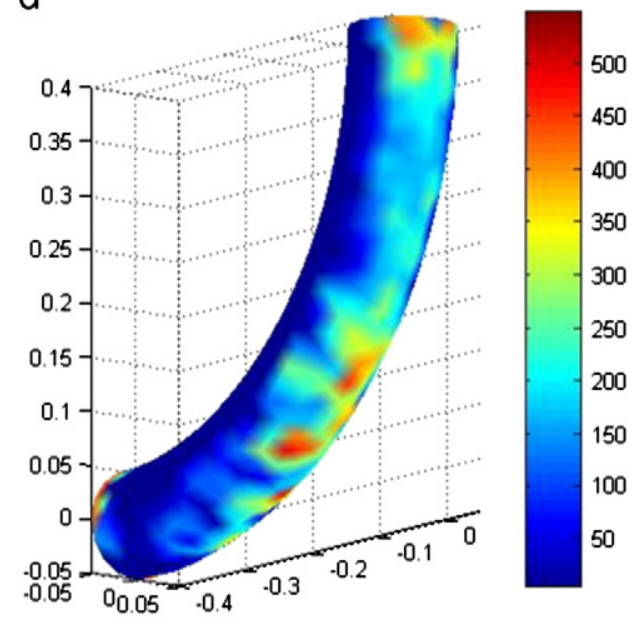

Fig. 4. The maximum impact force $(\mathrm{N})$ distribution of the elbow from the bottom view at slurry velocity: (a) $6 \mathrm{~m} / \mathrm{s}$; (b) $9 \mathrm{~m} / \mathrm{s}$; (c) $18 \mathrm{~m} / \mathrm{s}$; (d) $36 \mathrm{~m} / \mathrm{s}$.

the elbow makes the location of the second peak move downstream from the intersection point of the centerline of the inlet flow and the outer wall of the extrados. The third peak is due to the centripetal

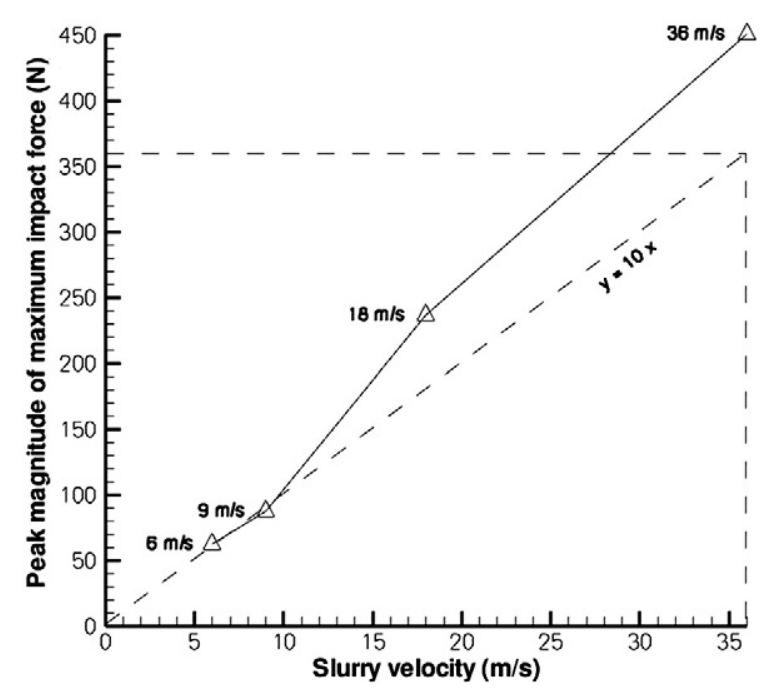

Fig. 5. Peak magnitude of the maximum impact force at different slurry velocities. force. In this study, we focus on the locations and the impact force on the former two peaks caused by direct strike of particles. When the slurry velocity is $6 \mathrm{~m} / \mathrm{s}$, the maximum erosive locations are observed

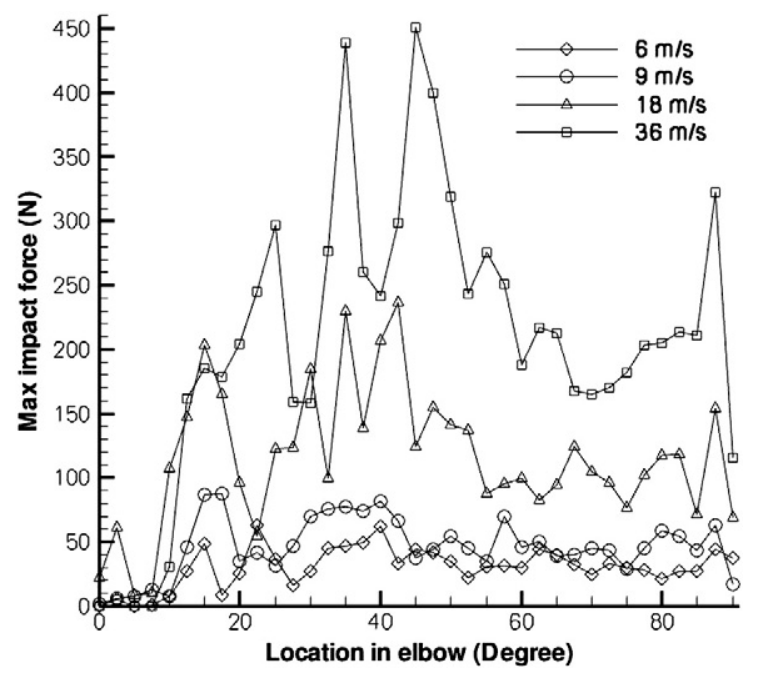

Fig. 6. The max impact force distribution on the outer wall of the elbow at different fluid velocities. 
at 15 and $42.5^{\circ}$, the interaction force is $48.2 \mathrm{~N}$ at first peak and $61.8 \mathrm{~N}$ at the second peak; when the slurry velocity is $9 \mathrm{~m} / \mathrm{s}$, the maximum erosive locations are observed at 17.5 and $42.5^{\circ}$, the interaction force is $87.5 \mathrm{~N}$ at the first peak and $81.0 \mathrm{~N}$ at the second peak; when the slurry velocity is $18 \mathrm{~m} / \mathrm{s}$, the maximum erosive locations are observed at 15 and $45^{\circ}$, the interaction force is $202.8 \mathrm{~N}$ at the first peak and $236.3 \mathrm{~N}$ at the second peak. When the slurry velocity is $36 \mathrm{~m} / \mathrm{s}$, the maximum erosive locations are observed at 15 and $47.5^{\circ}$, the interaction force is $185.0 \mathrm{~N}$ at the first peak and $450.6 \mathrm{~N}$ at the second peak. It can be seen from Fig. 6 that location of the first peak does not change very much when slurry velocity increases, but the location of the second peak moves to downstream caused by fluid-solid drag force when slurry velocity increases, which means that the lower layer of the particle flux from the inlet pipe strikes on the elbow directly then forms the first peak and the upper layer of the particle flux was dragged deeper into the elbow by the slurry flow and results in the location of the second peak moving deeper downstream, this trend is consistent with the experimental results by [1] and [6].

\subsubsection{Effect of the bend orientation on the puncture point location}

In this section, to study the effect of the bend orientation on the puncture point location, simulations were conducted by changing the direction of the gravity action and whereas the rest of the parameters are the same as the standard case. For the sake of comparison, in this section, results are drawn in this way that the inlet pipe was always at the left-down corner of the picture, the pipe which has the same direction with the gravity force was regarded as a vertical pipe, while the pipe which is perpendicular to the gravity force was regarded as a horizontal pipe.

Generally, the flow pattern has a great influence on the puncture point location, however it is extremely difficult to observe the flow pattern or obtain the interaction force in experiments online. Fig. 7(a), (b), (c), (d) indicates the particle movement in: no gravity considered (standard case), vertical to horizontally downward, horizontal to vertically inclined downward and horizontal to vertically downward pipe, respectively. In Fig. 7(a), the gravity action is ignored, it is shown that an obvious segregation is formed in the elbow and the particles glide cling to the outer wall due to the centripetal force. In Fig. 7(b), the gravity force has the same direction with the inlet pipe so has little effect on particle pattern in the inlet pipe, the gravity action results in the segregation layer of particles in the elbow thinner than that in Fig. 7(a), the impact angle is similar with that in the standard case. The effect of gravity action on the particles in the inlet pipe can be observed in Fig. 7(c) and (d), where the gravity force leads the particles to settle down on the bottom of the inlet pipe. In the elbow, the gravity force results in most of the particles moving away from the central axis of the horizontal pipe, the particle concentration region moves deeper into the bend due to sum action of gravity
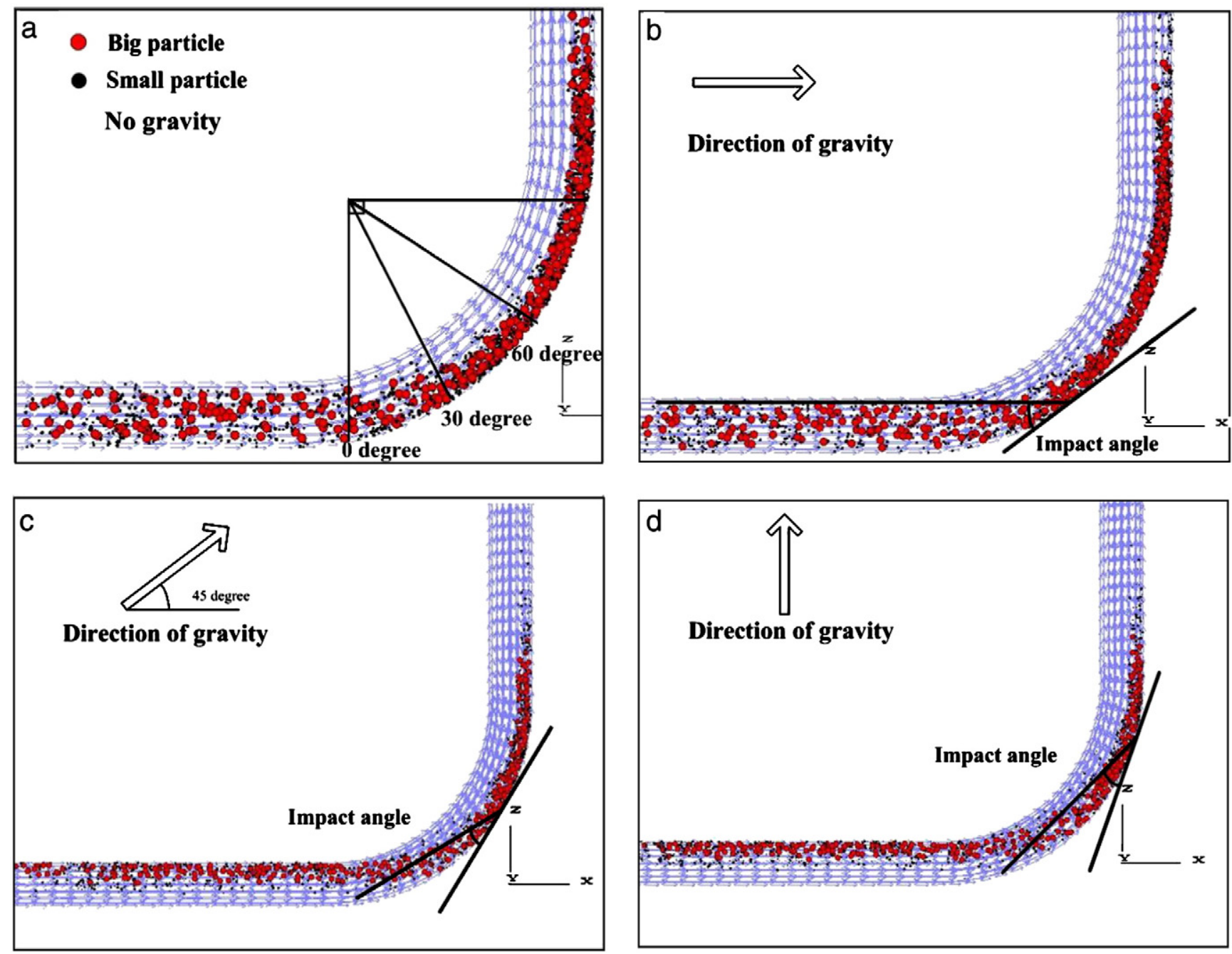

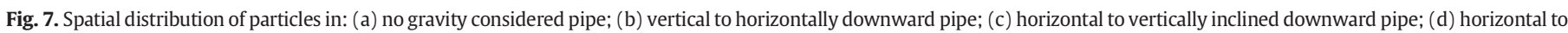
vertically downward pipe. 
and slurry drag force. This movement makes the first impact point of the particle flux move deeper into the bend and leads to a decrease of particle impact angle. This kind of biased particle distribution was also discussed in Deng's experiments [9].

Fig. 8 shows the maximum impact force distribution corresponding to Fig. 7. In Fig. 8(a), when the gravity action is ignored, the puncture point is observed at approximately $42^{\circ}$. In Fig. 8(b), the puncture point location is not obvious. This is due to the gravity action, the gravity force prevents the particles from bouncing back and makes the particles still gliding cling to the outer wall closely as shown in Fig. 7(b), therefore a durative wear takes place at nearly the entire outer wall of the elbow. In Fig. 8(c), the puncture point location is observed at approximately $60^{\circ}, 20^{\circ}$ downstream of the puncture point location in Fig. 8(a). And in Fig. 8(d), the puncture point location is observed at approximately $90^{\circ}$ or further. The focus of this study is on the wear process on the elbow, so wear pattern was only investigated in this region.

Fig. 9 shows the maximum impact force distribution at different bend orientations versus the location in elbow and compared with the standard case. It can be seen from Fig. 9(b) that the average magnitude of max impact force in the vertical to horizontally downward pipe is similar with that in the standard case, whereas the amplitude is smaller due to the gravity action, the interaction force from 60 to $90^{\circ}$ is higher than that in the standard case. In Fig. 9(c), the puncture location is observed at approximately $60^{\circ}$. The puncture location in Fig. 9(d) is observed at approximately $72^{\circ}$. From the four pictures in Fig. 9, it can be seen that the puncture point location is indeed significantly influenced by the bend orientation, the gravity force makes the puncture point location move deeper in a horizontal to vertically downward pipe, this phenomenon is consistent with the experimental results in [9]. Note that the interaction force at $0-12.5^{\circ}$ in Fig. 9(c) and $0-27^{\circ}$ in Fig. 9(d) is zero, which confirms that the gravity action makes the first impact point of the particle flux move deeper into the bend. However it shows in our results that the impact force at the puncture point location is lower than that in the standard case, this is different from the conclusion obtained in [9]. Deng [9] proposed that the horizontal to vertically downward pipe has the shortest service life than other bend orientations. However the impact force obviously depends on the bend radius to pipe diameter ratio and the slurry velocity employed. Suppose that in a horizontal to vertically downward pipe, given a sufficient low slurry velocity, the particles will directly drop down into vertical pipe, without any contacts forming between the a

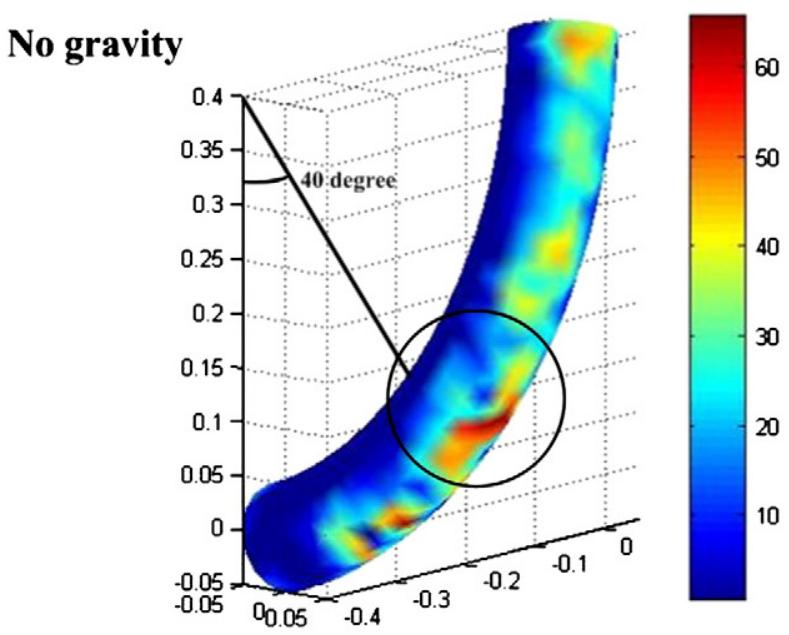

C

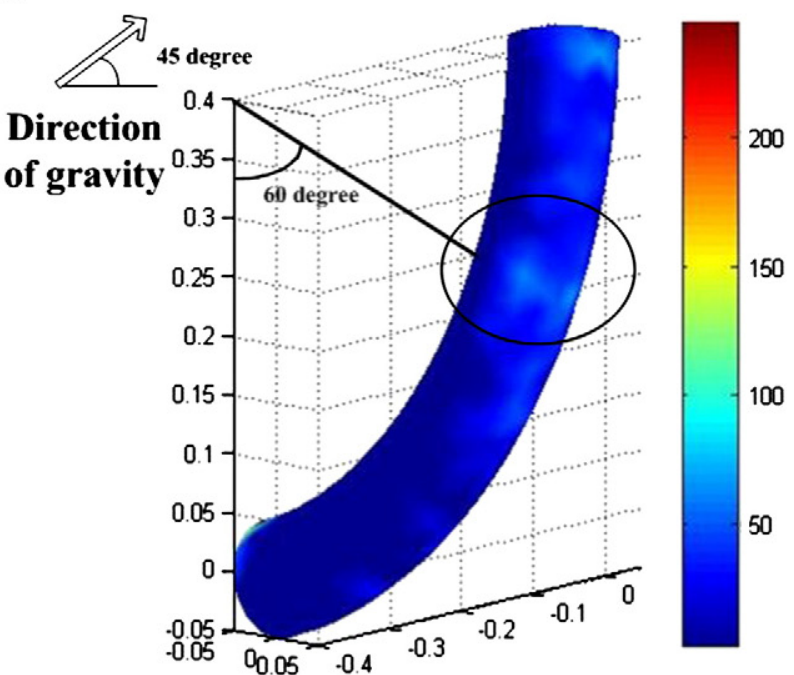

b

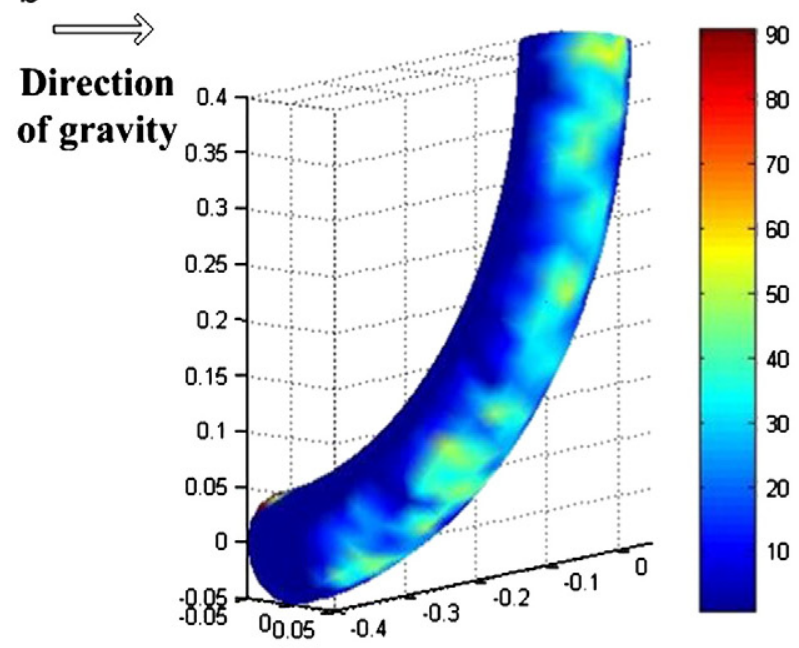

d

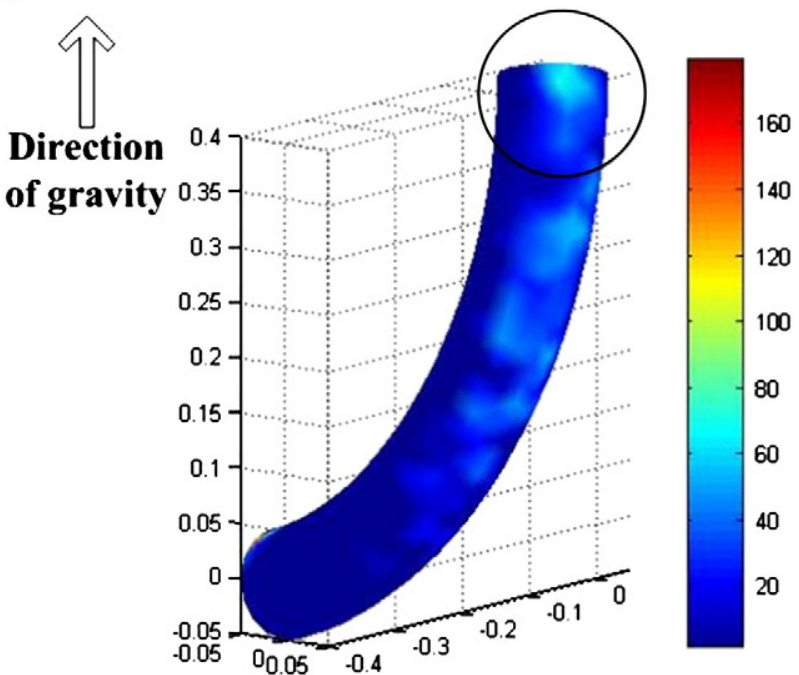

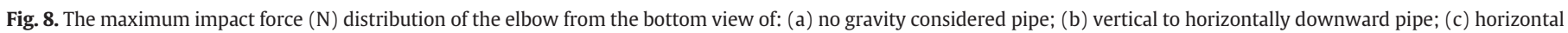
to vertically inclined downward pipe; (d) horizontal to vertically downward pipe. 
a

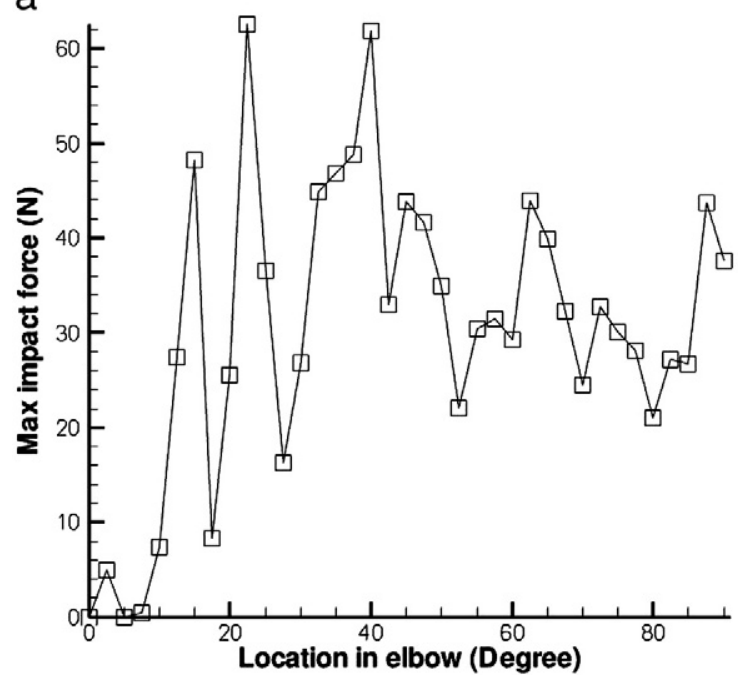

C

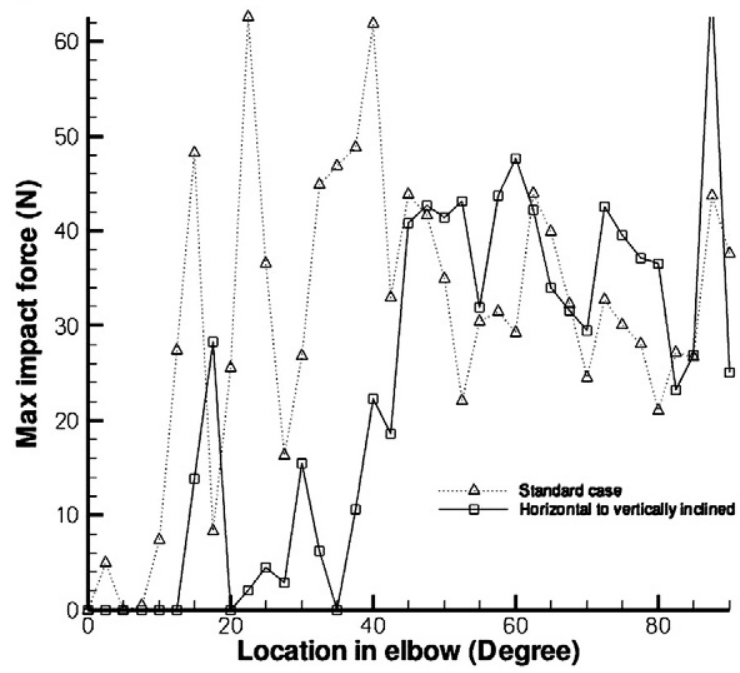

b

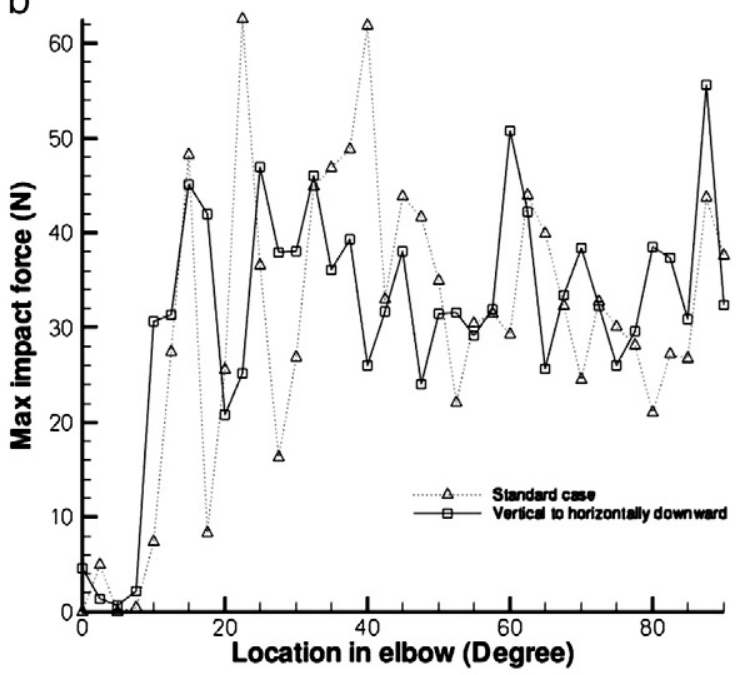

d

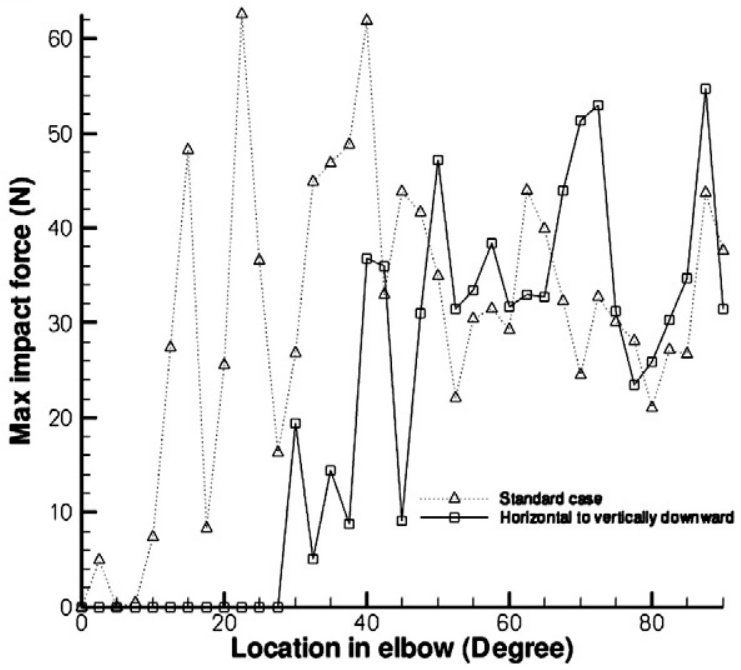

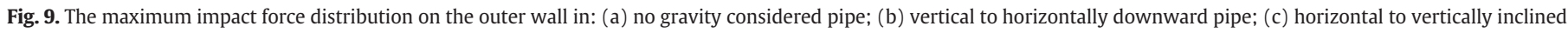
downward pipe; (d) horizontal to vertically downward pipe.

particles and the outer wall of the elbow. Furthermore, the fluid velocity in [9] is much higher than that in this study, and gas was employed as the carrier phase in [9] while the carrier phase employed in this study is liquid.

\subsubsection{Erosion investigation on $U$-shaped bend}

Earlier studies of fluid-solid flows have been carried out both experimentally $[1,6,9]$ and numerically $[7,23-25]$ to obtain information about fluid-solid behavior at $90^{\circ}$ bends, but there has not been very much research into erosion in U-shaped bend, especially on the pipe erosion. However they are widely used in many industrial applications such as pneumatic conveying dryer system [26,27]. In this section, to study the puncture point location on pipes with other angle, a U-shaped bend was established and simulations were conducted without considering the gravity action, the slurry velocity was $18 \mathrm{~m} / \mathrm{s}$.

Fig. 10(a) and (b) shows the spatial distributions of maximum and total impact force on the U-shaped bend, respectively. It can be seen from Fig. 10(a) that the maximum erosive location is observed at approximately $43^{\circ}$ (degree is defined in Fig. 7(a)) due to the direct strike of the particles from horizontal pipe, this location is similar with that in a $90^{\circ}$ elbow when the same slurry velocity is adopted. Another high wear region is observed at approximately $160^{\circ}$ due to the centripetal force. Fig. 10(b) shows the total impact force distribution on the U-shaped bend, it can be seen that, in the case of ignoring the gravity action, the later half of the U-shaped bend suffers more frequently but with lighter friction than the former half though the puncture point location is observed at the former half, which means the former half of the U-shaped bend has a shorter service life while the average thickness loss on the later half is higher. Fig. 11 illustrates the max impact force distribution versus the location in U-shaped bend. From Fig. 11, it can be seen that two peaks were observed, the first one is observed at $43^{\circ}$, the second one is observed at $160^{\circ}$.

\section{Concluding remarks}

Numerical simulations based on CFD and DEM have been conducted to study the solid-fluid multiphase flow problem in fluid transportation progress. Effects of the slurry velocity, bend orientation and angle of elbow on the puncture location were discussed. 
a
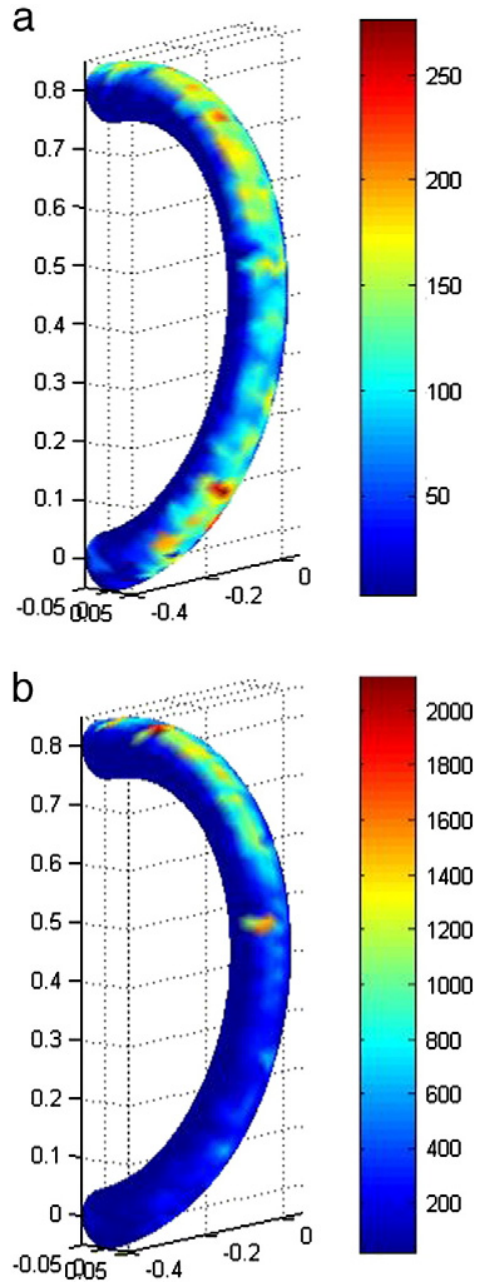

Fig. 10. Spatial distributions of (a) maximum impact force $(N)$ and (b) total impact force $(\mathrm{N})$ on $\mathrm{U}$-shaped bend.

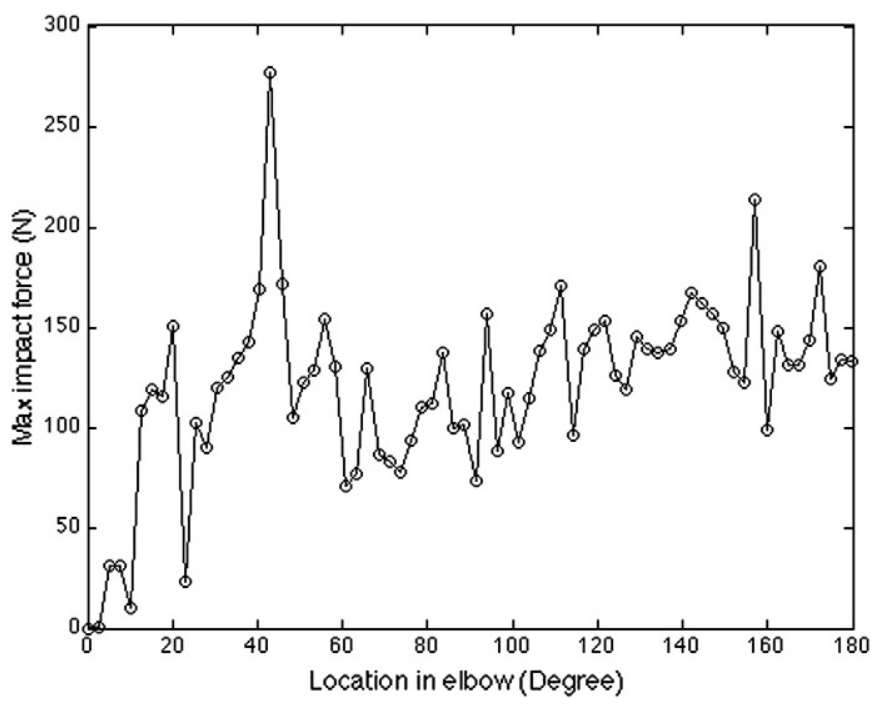

Fig. 11. The max impact force distribution on the outer wall of the U-shaped bend.
According to the results of the analysis, the following conclusions can be made:

1. The puncture point location is influenced by the slurry velocity, the location of the maximum erosive location moves to downstream when slurry velocity increases. The impact force is higher when the slurry velocity is higher.

2. The puncture point location is significantly influenced by the bend orientation. In this study, the gravity force makes the segregation layer thinner in the vertical to horizontally downward pipe compared with that in no-gravity case. In the horizontal to vertically downward pipe, the gravity action leads the particles to settle down on the bottom of the horizontal pipe and results in most of the particles moving away from the central axis of the horizontal pipe in the elbow. The gravity force makes the particle concentration region moves deeper into the bend due to sum action of the gravity and slurry drag force. This movement makes the first impact point of the particle flux move deeper into the bend.

3. In a U-shaped bend, the maximum erosive location is observed at approximately $40^{\circ}$ due to the direct strike of the particles, which is nearly same with the puncture location in the $90^{\circ}$ elbow. Whereas later half of the elbow suffers more frequently but with lighter friction than the former half. However it is important to note that the numerical predictions for U-shaped bend have not been compared to experimental data which is essential to be done before numerical work.

\section{Acknowledgement}

Hao Zhang would like to acknowledge the Hunan Provincial Innovation Foundation for Postgraduate under Grant No. CX2010B263. Yuanqiang Tan would like to thank NSFC of China under Grant No. 50675185, and the Program of New Century Excellent Talents (NCET06-0708) for the financial support to the research.

\section{References}

[1] Q.H. Mazumder, S.A. Shirazi, B. McLaury, Experimental investigation of the location of maximum erosive wear damage in elbows, ASME, Journal of Pressure Vessel Technology 130 (2008) 113031-113038.

[2] X. Chen, B.S. McLaury, S.A. Shirazi, Effects of applying a stochastic rebound model in erosion prediction of elbows and plugged tee, ASME, Fluids Engineering Division Meeting, Mentreal, Quebec, Canada, Paper No. FEDSM2002-31289, 2002.

[3] R.L. Stoker, Erosion due to dust particles in a gas stream, Industry and Engineering Chemistry 41 (1949) 1196-1199.

[4] G.P. Tilly, Erosion caused by airborne particles, Wear 14 (1969) 63-79.

[5] Q.H. Mazumder, S.A. Shirazi, B.S. McLaury, Prediction of solid particle erosive wear of elbows in multiphase annular flow-model development and experimental validations, ASME, Journal of Pressure Vessel Technology 130 (2008) 113031-113038.

[6] Selmer-Olsen S., Medium pressure flow studies of particulated and concurrent annular gas/liquid flow with relevance to material loss in unprocessed hydrocarbon systems. Third International Conference on Multiphase Flow, The Hague, Netherlands Paper No. K4.

[7] Y.Q. Tan, H. Zhang, D.M. Yang, et al., Numerical simulation of concrete pumping process and investigation of wear mechanism of the pipe wall, Tribology International 46 (1) (2012) 137-144.

[8] Burnett A.J., The use of laboratory erosion tests for the prediction of wear in conveyor bends, PhD Thesis, The Wolfson Centre for Bulk Solids Handling Technology, University of Greenwich, London, UK,1996.

[9] T. Deng, M. Patel, I. Hutchings, M.S.A. Bradley, Effect of bend orientation on life and puncture point location due to solid particle erosion of a high concentrated flow in pneumatic conveyors, Wear 258 (2005) 426-433.

[10] T.B. Anderson, R. Jackson, A fluid mechanical description of fluidised beds, Industrial and Engineering Chemistry Fundamental 6 (1967) 527-539.

[11] R. Di Felice, The voidage function for fluid-particle interaction systems, International Journal on Multiphase Flow 20 (1994) 153-159.

[12] P.A. Cundall, in: Led Muller (Ed.), A computer model for simulating progressive large scale movements in blocky system, Proceedings of the Symposium International Society of Rock Mechanics, 1, Balkama A A, Rotterdam, 1971, pp. 8-12.

[13] A.B. Yu, B.H. Xu, Particle-scale modeling of gas-solid flow in fluidization, Journal of Chemical Techology and Biotechnology 78 (2003) 111-121.

[14] H.H. Hu, Direct simulation of flows of solid-liquid mixtures, International Journal of Multphase Flow 22 (1996) 335-352. 
[15] T.W. Pan, D.D. Joseph, R. Bai, et al., Fluidization of 1204 spheres: simulation and experiment, Journal of Fluid Mechanics 451 (2002) 169-191.

[16] B.K. Cook, D.R. Noble, J.R. Williams, A direct simulation method for particle fluid systems, Engineering Computations 21 (2004) 151-168.

[17] J.A.M. Kuipers, W.P.M. van Swaaij, Application of computational fluid dynamics to chemical reaction engineering, Reviews in Chemical Engineering 13 (1997) 1-118.

[18] Itasca Consulting Group Inc., PFC3D (Particle Flow Code in 3 Dimensions). Version 3.10. User manual. Minneapolis, Minnesota, 2005.

[19] Itasca Consulting Group Inc., PFC3D (Particle Flow Code in 3 Dimensions) CCFD Add-on. Version 4.00. User manual. Minneapolis, Minnesota, 2008.

[20] Z.J. Zhao, Construction Technology of Concrete Pumping, China Architecture Building Press, Beijing, 1988.

[21] S.V. Patankar, Numerical Hear Transfer and Fluid Flow, McGraw-Hill, New York, 1980, pp. 131-147.
[22] K.D. Kafui, C. Thornton, M.J. Adams, Discrete particle-continuum fluid modeling of gas-solid fluidized beds, Chemical Engineering Science 57 (2002) 2395-2410.

[23] B. Bozzini, M.E. Ricotti, M. Boniardi, et al., Evaluation of erosion-corrosion in multiphase flow via CFD and experimental analysis, Wear 255 (2003) 237-245.

[24] K.W. Chu, A.B. Yu, Numerical simulation of the gas-solid flow in three-dimensional pneumatic conveying bends, Industry and Engineering Chemistry Research 47 (2008) 7058-7071.

[25] J.Y. Tu, C.A.J. Fletcher, Numerical simulation of turbulent gas-solid particle flow in a 90 degree-bend, AICHE Journal 41 (10) (1995) 2187-2197.

[26] C. Fyhr, A. Rasmuson, Mathematical model of a pneumatic conveying dryer, AICHE Journal 43 (1997) 2889-2902.

[27] M. Hidayat, A. Rasmuson, Some aspects on gas-solid flow in a U-bend: numerical investigation, Powder Technology 153 (2005) 1-12. 